\title{
Effects of a hydroxyapatite coating on the stability of endosseous implants in rabbit tibiae
}

\section{Wpływ powłoki hydroksyapatytowej na stabilizację wszczepów śródkostnych w piszczelach królików}

\author{
Magdalena Łukaszewska-Kuska ${ }^{1, A-F}$, Piotr Krawczyk ${ }^{2, A-F}$, Agnieszka Martyla ${ }^{3, B, C, E, F}$, Wiesław Hędzelek ${ }^{4, A, E, F}$, Barbara Dorocka-Bobkowska, ${ }^{1, A, E, F}$ \\ 1 Department of Gerodontology and Oral Pathology, Poznan University of Medical Sciences, Poland \\ ${ }^{2}$ Institute of Chemistry and Technical Electrochemistry, Poznan University of Technology, Poland \\ ${ }^{3}$ Institute of Non-Ferrous Metals, Central Laboratory of Batteries and Cells, Poznań, Poland \\ ${ }^{4}$ Department of Prosthodontics, Poznan University of Medical Sciences, Poland \\ A - research concept and design; $\mathrm{B}$ - collection and/or assembly of data; $\mathrm{C}$ - data analysis and interpretation; \\ $D$ - writing the article; $E$ - critical revision of the article; $F$ - final approval of the article
}

Address for correspondence

Magdalena Łukaszewska-Kuska

E-mail:m.lukaszewska.kuska@gmail.com

Funding sources

The Polish Ministry of Science and Higher Education research project No. N403 010 32/0480.

Conflict of interest

None declared

Received on November 28, 2018

Reviewed on January 13, 2019

Accepted on February 8, 2019

Published online on June 28, 2019

Cite as

Łukaszewska-Kuska M, Krawczyk P, Martyla A, Hędzelek W, Dorocka-Bobkowska B. Effects of a hydroxyapatite coating on the stability of endosseous implants in rabbit tibiae. Dent Med Probl. 2019;56(2):123-129. doi:10.17219/dmp/103851

DOI

$10.17219 / \mathrm{dmp} / 103851$

Copyright

○) 2019 by Wroclaw Medical University

This is an article distributed under the terms of the

Creative Commons Attribution 3.0 Unported License (CC BY 3.0)

(https://creativecommons.org/licenses/by/3.0/)

\begin{abstract}
Background. A dental implant surface which would promote rapid and strong osseointegration is a key factor of success in modern implantology. To achieve this goal, different implant surface modifications are developed. A hydroxyapatite $(\mathrm{HA})$ coating changing a bioinert titanium surface into bioactive is one of them.

Objectives. The objective of the study was to investigate the effects on bone osseointegration in rabbits resulting from the application of a HA coating deposited on titanium endosseous implants using a modified electrochemical method.

Material and methods. Titanium implants with $\mathrm{HA}$ coatings and controls with $\mathrm{Al}_{2} \mathrm{O}_{3}$ grit-blasted surfaces were embedded into rabbit tibiae. The chemical composition, roughness and morphology of the implants were determined. Implant stability tests were performed, and the Periotest ${ }^{\circledR}$ value (PTV) and the implant stability quotient (ISQ) value for Osstell Mentor were recorded in order to evaluate the osseointegration.
\end{abstract}

Results. The surface characterization of the implants revealed a microstructure with an arithmetical mean height (Sa) in the range of $0.71-1.04 \mu \mathrm{m}$. The HA coating was free of contamination, whereas the controls were enriched with corundum. After healing, a statistically significant increase in the mean ISQ and a decrease in the mean PTV for the HA-coated implants was observed. In the case of the control implants, only PTV decreased significantly with time.

Conclusions. The present study found that implant surface properties affected implant stability as determined by Osstell and Periotest measurements. The HA coating reported herein was found to have chemical and physical properties which appear to improve osseointegration compared to grit-blasted implants.

Key words: dental implants, surface properties, electrochemical techniques, durapatite

Słowa kluczowe: wszzzepy dentystyczne, włáśiiwości powierzchni, techniki elektrochemiczne, durapatyt 


\section{Introduction}

The development of a firm implant/bone interface is believed to be a major prerequisite for the short- and long-term clinical function of dental implants. ${ }^{1,2}$ Different implant geometries and surfaces as well as host site conditions may affect the interface development and its characteristics. ${ }^{3,4}$ Many strategies have been used to improve osseointegration and to shorten the healing period of titanium implants. One of those strategies is changing bioinert titanium surface into bioactive one. Hydroxyapatite (HA) has been used for many years as a bioactive implant coating to improve osseointegration. ${ }^{5-7}$ It has a large capacity for adsorbing proteins, improves osteoblast proliferation, enhances bone formation, and reduces bone loss..$^{8-10}$ These properties induce a more rapid fixation and stronger bonding between the host bone and the implant and are conducive to uniform bone ingrowth at the bone-implant interface. ${ }^{6}$ The most common technique of applying HA coating is the plasma-spraying technique but several problems such as delamination and disintegration with the formation of debris particles have been reported. ${ }^{11}$ Therefore, alternative HA coating processes have been extensively researched in order to avoid these undesirable effects of plasma application. One of the most promising methods is electrochemical deposition. Recently, we presented a modified electrochemical method of coating titanium implants with HA. ${ }^{5}$ The obtained coating was found to be highly pure, homogenous HA, which was uniform, crack-free and thin. Moreover, its moderate surface roughness and coatings crystallinity was potentially conducive to tissue reaction.

The objective of the study was to investigate the effects on osseointegration resulting from the application of a HA coating deposited on titanium implants using a modified electrochemical method based on the changes of implants stability representing osseointegration status.

\section{Material and methods}

\section{Implant design and surface preparation}

Twenty-eight commercially pure titanium class IV screw implants $4 \mathrm{~mm}$ in diameter and $7 \mathrm{~mm}$ in length were used (Osteoplant ${ }^{\circledR}$, Dębica, Poland). Implants were manufactured exclusively for the purpose of this study from commercially pure titanium class IV wire. Titanium wire, apart from titanium, consisted of $54 \mathrm{ppm}$ of $\mathrm{H}, 0.285 \%$ of $\mathrm{O}, 0.01 \%$ of C, $0.14 \%$ of Fe and $0.007 \%$ of $\mathrm{N}$ according to the manufacturer. All the implants were sandblasted with corundum grit $\left(\mathrm{Al}_{2} \mathrm{O}_{3}\right)$ with a diameter of 53-75 $\mu \mathrm{m}$. The $\mathrm{Al}_{2} \mathrm{O}_{3}$ powder was composed of $98.5 \% \mathrm{Al}_{2} \mathrm{O}_{3}$ with $0.18 \%$ $\mathrm{SiO}_{2}, 0.01 \% \mathrm{TiO}_{2}, 0.007 \% \mathrm{Fe}_{2} \mathrm{O}_{3}$, and $0.001 \% \mathrm{CaO}$. Fourteen implants were left with an $\mathrm{Al}_{2} \mathrm{O}_{3}$ grit-blasted surface. Fourteen other implants were coated with HA using electrochemical deposition. Prior to electrodeposition, the implants were etched with $0.5 \mathrm{M} \mathrm{H}_{2} \mathrm{SO}_{4}$. The process of HA electrodeposition was carried out using an AUTOLAB PGSTAT $302 \mathrm{~N}$ potentiostat-galvanostat (Ecochemie, Utrecht, the Netherlands) with a 2-electrode system in a galvanostatic mode, with a current of $5 \mathrm{~mA}$. The implant was used as the working electrode, and a platinum mesh served as a counter-electrode. The electrolyte consisted of $2.08 \times 10^{-4} \mathrm{M} \mathrm{CaCl}_{2}, 1.25 \times 10^{-4} \mathrm{M} \mathrm{NaH}_{2} \mathrm{PO}_{4}$ and $0.1 \mathrm{M} \mathrm{NaCl}$ in distilled water. The $\mathrm{pH}$ was adjusted to 6.3 with $\mathrm{NaOH}$ solution. The process was carried out for $105 \mathrm{~min}$ at a temperature of $100^{\circ} \mathrm{C}$. A $100 \mathrm{~mL}$ 3-neck flask was used as an electrochemical reactor and was immersed in a thermostated oil bath.

After surface preparation, all the implants were subjected to ultrasonic washing in a surfactant for $15 \mathrm{~min}$ at $55^{\circ} \mathrm{C}$, followed by 2-propranol washing for $15 \mathrm{~min}$ at $22^{\circ} \mathrm{C}$, disinfectant washing for $15 \mathrm{~min}$ at $22^{\circ} \mathrm{C}$, and finally to washing twice in distilled water for $15 \mathrm{~min}$ at $55^{\circ} \mathrm{C}$. The implants were then double-packed and sterilized with radiation from an electron accelerator with a radiation dose of $25 \mathrm{kGy}$.

\section{Physicochemical characteristics of implant surface}

The chemical composition of the surface was evaluated using X-ray photoelectron spectroscopy (XPS). The measurements were made using a photoelectron spectrometer ESCALAB-210 VG Scientific Ltd, East Grinstead, UK) with $\mathrm{Al} \mathrm{Ka}$ radiation $(1486.6 \mathrm{eV})$ from an X-ray source, operating at $15 \mathrm{kV}$ and $20 \mathrm{~mA}$. Survey spectra were recorded in the energy range from $0 \mathrm{eV}$ to $1350 \mathrm{eV}$, with a $0.4 \mathrm{eV}$ step. High-resolution spectra were recorded with a $0.1 \mathrm{eV}$ step, $100 \mathrm{~ms}$ dwell time and $20 \mathrm{eV}$ pass energy. A $90^{\circ}$ take-off angle was used in all measurements. Curve fitting was performed using the AVANTAGE software (Thermo Electron; Thermo Fisher Scientific, Waltham, USA), which describes each component of the complex envelope as a Gaussian-Lorentzian sum function. A constant $0.3 \pm 0.05 \mathrm{G} / \mathrm{L}$ ratio was used and the background was fitted using a nonlinear Shirley model. Scofield sensitivity factors and a measured transmission function were used for quantification. Aromatic carbon C1s peak at $285 \mathrm{eV}$ was used as a reference of binding energy. ${ }^{12}$

The implant surface morphology was examined with a scanning electron microscope (SEM) Tescan Vega (Tescan, Brno, Czech Republic) and Zeiss EVO 25 (Carl Zeiss, Oberkochen, Germany).

Surfaces roughness was measured with an optical WYKO ${ }^{\circledR}$ NT1100 profilometer (Veeco Instruments, Plainview, USA) in VSI Mode, and the measured area was $0.9 \times 1.2 \mathrm{~mm}$ under $\times 20$ magnification. The WYKO Vision software v. 3.0 for NT-1100 was used. To remove errors of form and waviness, the removal shape function Plane Fit was used to remove linear tilt from surface 
measurements. After that, the S-Parameters Analysis was used to evaluate value of parameters. The surface roughness of the examined implants was measured at 5 random locations in the integration to be part of the implant.

\section{Animal study}

The in vivo animal study was carried out in accordance with the guidelines for the care and ethical use of laboratory animals and was approved by the regional animal Ethics Committee of the Poznan University of Life Sciences, Poland (approval No. 60/2007). Adequate measures were taken to minimize the pain or discomfort of the animals. Fourteen 6-month-old white New Zealand female rabbits weighing about $4 \mathrm{~kg}$ were used. Each animal received 2 implants of the same size. One implant had an HA coating prepared using the above electrochemical deposition method. The other implant had an $\mathrm{Al}_{2} \mathrm{O}_{3}$ grit-blasted surface. The left limb was operated in all subjects. Mesially HA-coated implant was placed and $\mathrm{Al}_{2} \mathrm{O}_{3}$ blasted implant was placed distally. The surgical procedure was performed under sterile conditions by 1 dental surgeon. General anesthesia was induced with an intramuscular injection of ketamine (50 $\mathrm{mg} / \mathrm{kg}$ body weight) and xylozyn (10 $\mathrm{mg} / \mathrm{kg}$ body weight). At the surgical site, infiltrate anesthesia was induced with an injection of $1 \mathrm{~mL}$ lignocain + noradrenaline 1:10,000. After gentle skin preparation, the fascia and periosteum on the medial anterior surface of the medial tibial epiphysis were exposed. For implant bed preparation, Surgical XT (NSK, Kanuma, Japan) dental unit was used. The 2 implant beds were prepared using $2 \mathrm{~mm}$ and $2.7 \mathrm{~mm}$ burs with external saline irrigation applied for drilling with a temperature of about $20^{\circ} \mathrm{C}$. Osteoplant burs were used for this study. The burs used were new and every new bur after the first use was reused 6 times. The maximum $800 \mathrm{rpm}$ was used. The beds were separated with a $10 \mathrm{~mm}$ distance. Implants were inserted into the beds with a torque spanner until the level of implants was level with the bone surface. After implant placement, the periosteum, fascia and skin were sutured with Dexon ${ }^{\circledR} 4.0$ sutures. To prevent infection, intramuscular injections of $20 \mathrm{mg}$ cefuroximum per $1 \mathrm{~kg}$ body weight and neomycine spray were applied at the surgical site and administered twice daily for a week. To prevent post-operative pain, ketoprofen ( $1 \mathrm{mg} / \mathrm{kg}$ body weight) was given for a week. After a 2-week healing period, the animals were sacrificed with pentobarbital $(1 \mathrm{~mL} / \mathrm{kg}$ body weight) following general anesthesia with xylozyn (10 mg/kg body weight). The implants were exposed and implant stability was evaluated (vide infra).

The rabbits' bone metabolism and healing is about twice as fast as humans, thus a 2-week healing period in rabbits may correspond with 4 weeks in humans. This healing time in humans is the most critical moment for the stability of the implants, when primary stability decreases and secondary stability is still low.

\section{Implant stability testing}

Implant stability tests were carried out using Periotest $S^{\circledR}$ (Siemens AG, Bensheim, Germany) and Ostell Mentor ${ }^{\circledR}$ (Integration Diagnostics AB, Göteborg, Sweden) devices.

The Periotest has been thoroughly studied and advocated as a reliable method for determining implant stability. ${ }^{13-16}$ The Periotest measures implant mobility by percussing an abutment attached to the implant with an electromagnetically driven and electronically controlled rod fitted to the instrument. The contact time between the test object and tapping rod was measured with an accelerometer. The signals were then converted to a unique value called the Periotest value (PTV), which is related to the damping characteristics of tissues surrounding the teeth or implants. ${ }^{17}$ Periotest values ranging from -8 to +50 . The PTV is a measure of clinical stiffness. As the PTV values increase, implant stability is deemed to decrease. The measurements were taken at the same point of the abutment screwed to the implants. During the measurements, the Periotest handpiece was held perpendicularly to the abutment axes. All measurements were conducted by the same person. Care was taken to control the precise point and angle of the percussion unit (Fig. 1).

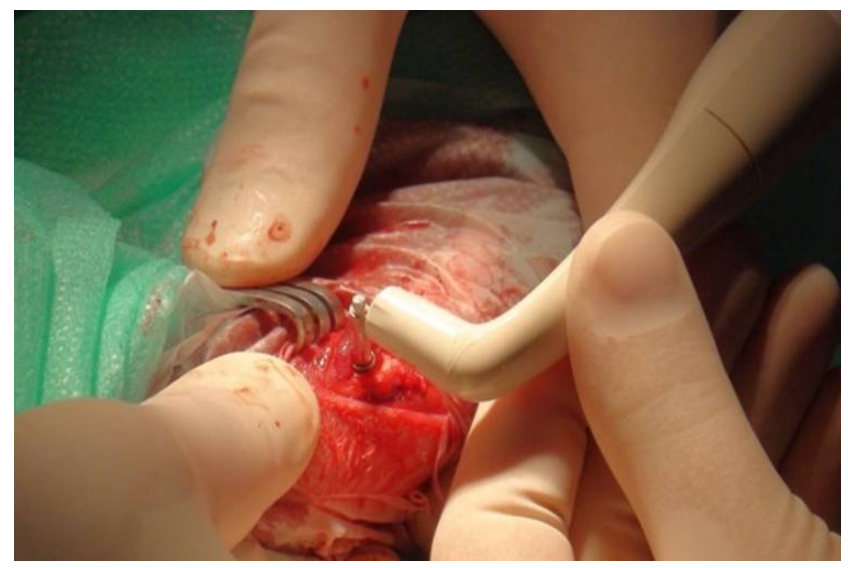

Fig. 1. Implant stability test with an Ostell device. Measurements were taken in 2 directions, with the instrument parallel and perpendicular to the longitudinal axis of the tibia. The mean ISQ values were recorded. All measurements were conducted by the same person

The Ostell Mentor is a device which uses resonance frequency analysis (RFA) to evaluate implant stability. The RFA utilizes a small Smart Peg transducer that is attached to the implant with a screw utilizing the internal threads of the implant. The transducer comprises of 2 piezoceramic elements, one of which is vibrated by a sinusoidal signal and the other serves as a receptor for the signal. Resonance peaks from the received signal indicate the first flexural (bending) resonance frequency of the measured object. The RFA values are expressed as implant stability quotients (ISQ), ranging from 1 to 100 
and relate to clinical stiffness. Implant stability increases with increasing ISQ value. The measurements were taken in 2 directions, with the instrument parallel and perpendicular to the longitudinal axis of the tibia. The mean ISQ values were recorded and all measurements were conducted by the same person (Fig. 2).

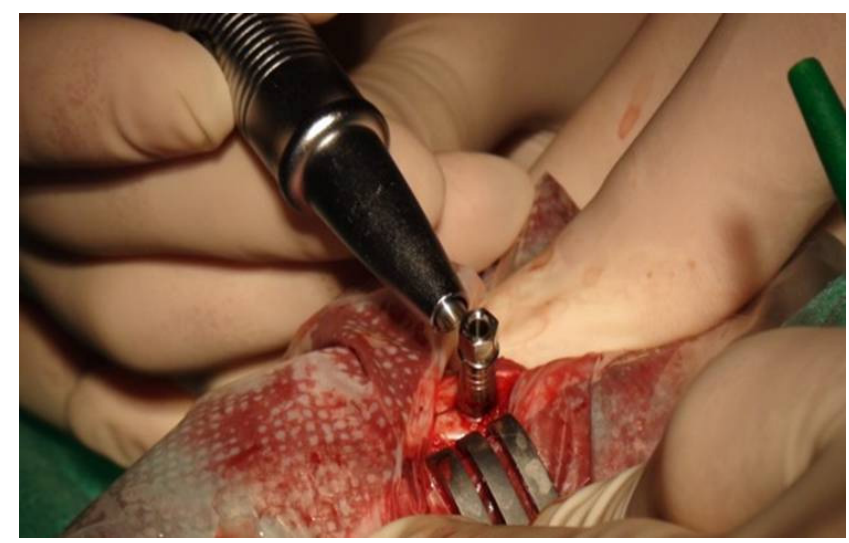

Fig. 2. Implant stability test with a Periotest device. Measurements were taken at the same point of the abutment screwed to the implants. During measurements the Periotest handpiece was always held perpendicular to the abutment axes. All measurements were conducted by the same person

\section{Statistical analysis}

The data was reported as the mean value \pm standard deviation $(S D)$. The statistics software STATISTICA v. 10.0 (Statsoft, Tulsa, USA) was used for all statistical analyses. The Shapiro-Wilk test was used to determine whether ISQ and PTV results were in accordance with normal distribution. For those values which were within the normal distribution, the t-Student's test was used; for those which were not, Wilcoxon's test was used to determine the existence of statistically significant differences between the 2 groups of implants. To determine whether implants stability increased with time, Spearman's correlation was used. The level of significance was determined as $p<0.05$.

\section{Results}

\section{Surface analysis}

The chemical composition analysis of coated implants revealed HA to be the principal component of the electrodeposited coating with only small amounts (up to $1 \%$ ) of $\mathrm{F}, \mathrm{Si}$, $\mathrm{N}$, and Na detected as surface impurities. The grit-blasted implant surface was composed of $\mathrm{Ti}$ and $\mathrm{O}$ with $\mathrm{Al}$ incorporated into the oxide layer during the grit-blasting procedure; in addition, carbon impurities were also detected.

Optical profilometry showed a surface roughness with $\mathrm{Sa}=1.04 \pm 0.06 \mu \mathrm{m}$ for HA-coated implants and $\mathrm{Sa}=0.74 \pm 0.03 \mu \mathrm{m}$ for the grit-blasted implants.
Scanning electron microscopy analysis revealed a uniform, integrated layer of rod-like HA crystals on the titanium surface with the longitudinal axes parallel to the implant surface for HA-coated implants (Fig. 3). In the case of the grit-blasted implants, SEM analysis of the surface revealed irregular, heterogeneous, intensively expanded, highly diverse notches and sharp edges with hollows (Fig. 4).

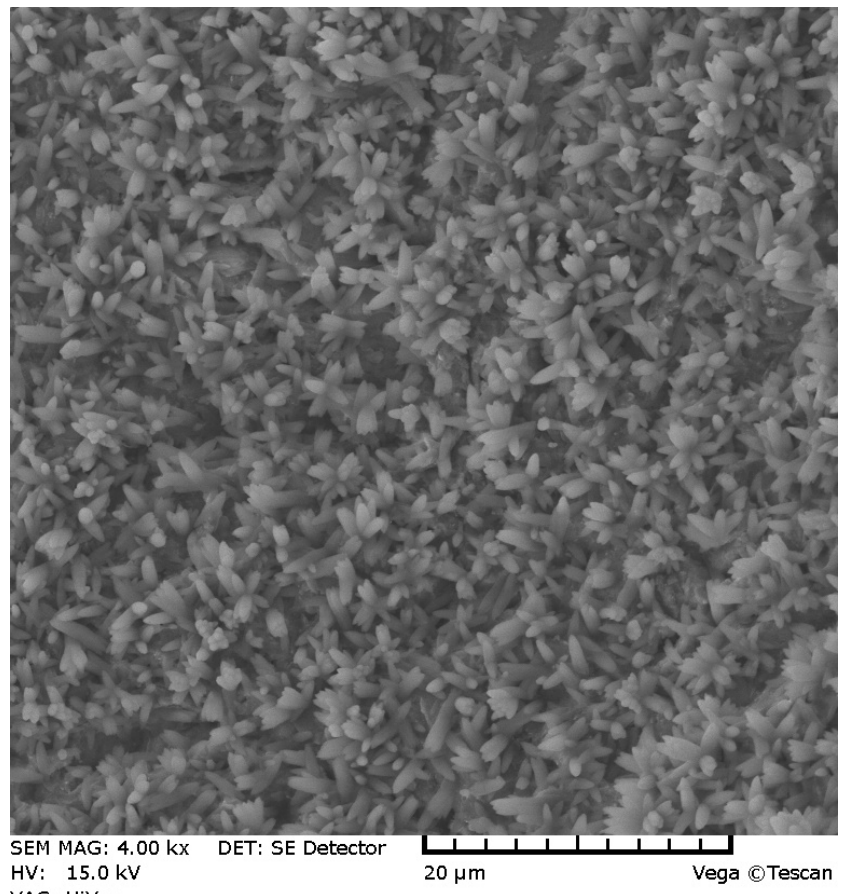
VAC: HiVac

Fig. 3. SEM micrograph of hydroxyapatite coating electrochemically deposited on titanium implant ( $\times 4,000$ magnification).

Radiation source - Tungsten heated cathode, kV level - 15.00



Fig. 4. SEM micrograph of $\mathrm{Al} 2 \mathrm{O} 3$ grit-blasted surface of titanium implant ( $\times 3,000$ magnification). Radiation source - Tungsten heated cathode, kV level - 15.00

A detailed analysis of hydroxyapatite coating deposited on titanium implants using a modified electrochemical method was presented in a previous article. ${ }^{5}$ 


\section{Implant stability tests}

Implant stability tests at the time of implantation produced mean PTV values of $12.58(S D=9.04)$ for the implants coated with HA and $7.83(S D=5.01)$ for the gritblasted implants. The mean ISQ values for the coated implants were $63.89(S D=2.17)$ and for grit-blasted implants $70(S D=3.74)$. No statistical significance was noted between the 2 groups of implants, either in the PTV values $(p=0.06)$ or in the ISQ values $(p=0.11)$. After 2 weeks of healing, the implant stability test revealed a decrease in the PTV values of both implant groups. Mean PTV values for the coated implants and for grit-blasted implants were $6.88(S D=8.11)$ and $3.13(S D=3.64)$, respectively. The mean ISQ values of both groups of implants increased to $69.85(S D=2.05)$ for the implants coated with HA and $72.25(S D=4.03)$ for sandblasted implants. No statistical significance was noted between the 2 groups of implants either in the PTV values $(p=0.11)$ or ISQ values $(p=0.22)$.

For the PTV values, statistically significant differences were noted between the measurements made between the time of implantation and the time of the animal sacrifice for the $\mathrm{Al}_{2} \mathrm{O}_{3}$ grit-blasted implants $(p=0.01)$ and for the HA-coated implants $(p=0.04)$ (Fig. 5).

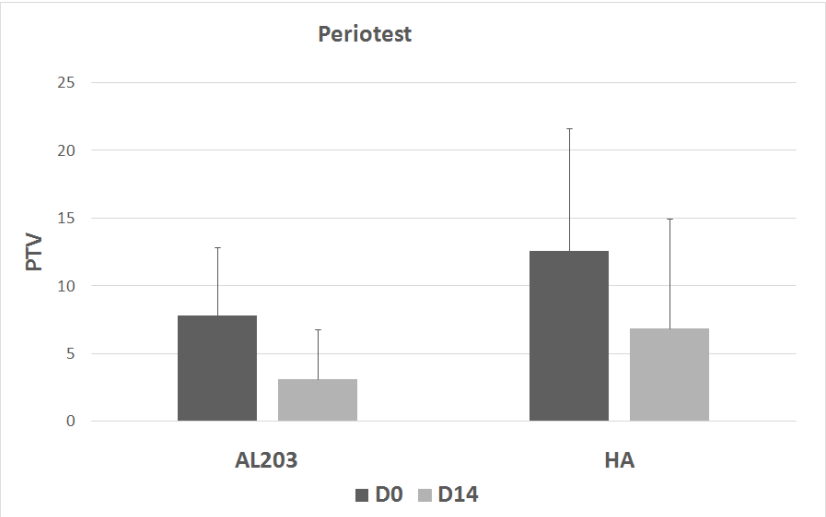

Fig. 5. Periotest values of HA-coated and sandblasted implants at the time of implantation and after 2 weeks of healing. Each value is a mean \pm standard deviation (SD). Statistically significant differences were noted between the measurements made between the time of implantation and the time of the animal sacrifice for the $\mathrm{Al}_{2} \mathrm{O}_{3}$ grit-blasted implants $(p=0.01)$ and for the HA-coated implants $(p=0.04)$

For the ISQ values, statistically significant differences were noted for the measurements made between the time of implantation and the time of the animal sacrifice for the HA coated implants $(p=0.006)$, while for the gritblasted implants the increase in the ISQ values was not significant $(p=0.15)$ (Fig. 6).

\section{Discussion}

Development of dental implantology is focused, among other things, on designing active surfaces for the implant and conditioning the acceleration of the integration of the



Fig. 6. Implant stability quotients values of HA-coated and sandblasted implants at the time of implantation and after 2 weeks of healing. Each value is a mean \pm standard deviation (SD). Statistically significant differences were noted for the measurements made between the time of implantation and the time of the animal sacrifice for the HA-coated implants $\left(p=0.006\right.$ ), while for the $\mathrm{Al}_{2} \mathrm{O}_{3}$ grit-blasted implants the increase in the ISQ values was not significant $(p=0.15)$

implant with the bone. To this end changes have been made to both the implant surface roughness and its chemical composition. Surface characterization of the implants used in this study revealed microstructured surfaces characterized as smooth for $\mathrm{Al}_{2} \mathrm{O}_{3}$ blasted implants and moderately rough for $\mathrm{HA}$-coated implants according to Wennerberg's classification; there were also considerable differences in surface chemistry between the HA coated and $\mathrm{Al}_{2} \mathrm{O}_{3}$ blasted implants. ${ }^{17}$

With regard to implant placement, neither ISQ nor PTV values indicated significant differences in primary stability between the 2 implant groups. After a healing time of 2 weeks, the implant stability as measured by Ostell and Periotest systems significantly increased for the HA-coated implants. In the case of the $\mathrm{Al}_{2} \mathrm{O}_{3}$ grit-blasted implants after 2 weeks healing time, the implant stability increased significantly only in terms of the Periotest system.

A statistically significant increase of both parameters for the HA-coated implants after healing time suggested a more favorable effect on osseointegration of the implants provided by the electrodeposited HA coating. That effect is probably due to the chemical composition of the coatings. Calcium phosphates, especially HA, have the potential for adsorbing large amounts of fibronectin and vitronectin on the surface, which increases the osteoblast adhesion and bone formation. ${ }^{18}$ Calcium phosphate also increases osteoblast proliferation, which increases the bioactivity of the coatings. ${ }^{19}$ Calcium ions enable the formation of a biochemical bond between the implant and the bone, which results in faster and more intense osseoinegration. ${ }^{18-20}$ Phosphate groups, on the other hand, provide potential chemical bonding sites for calcium ions and for the hydroxyapatite of the bone matrix during biological mineralization and are responsible for biochemical interaction between the implant and the bone (not just mechanical interlocking as in case of non-chemically modified surfaces). ${ }^{21}$ 
A positive HA coating effect on osseointegration was also reported by Geurs and Roynestal. ${ }^{22,23}$ In the Geurs study, threaded and cylindrical HA coated implants were compared to threaded titanium plasma sprayed implants. HA-coated implants underwent a more rapid initial decrease in micromobility compared to their uncoated counterparts. ${ }^{22}$ Roynesdal et al. found that HA-coated cylindrical implants had higher stability parameters than TPS or titanium threaded implants. ${ }^{24}$ This effect in the early stages of healing may be due to a firmer bone-to-implant contact. Positive effects of $\mathrm{Ca}$ and $\mathrm{P}$ ions on implant osseointegration manifested as increased implant stabilization was also reported by Sul and derived from the removal torque values in rabbit tibiae. ${ }^{24}$ Meraw et al., in a histological comparison, reported greater bone-to-implant contact early in the healing process for HA-coated implants in comparison with as-machined implants retrieved from dogs. ${ }^{25}$ This difference has been associated with the chemical composition of coated implants rather than coating surface roughness. ${ }^{20,26}$

Implant surface roughness affects osseointegration and surfaces with $\mathrm{Sa}=1-2 \mu \mathrm{m}$ are most effective. ${ }^{17}$ Although rougher HA-coated implants presented statistically significant increases of both ISQ and PTV values, an improvement in osseointegration was attributed to the surface chemistry, since the difference in the implant roughness was small. Sul et al. found no relationship between implant stability and surface roughness from 6 groups of implants with Sa ranging from $0.69 \mu \mathrm{m}$ to $1.34 \mu \mathrm{m} .{ }^{27}$ Instead, higher mean ISQ values were observed for surface chemistry-modified implants than for the topographically modified implants. ${ }^{27}$ Also, no relationship between implant stability and surface roughness were noted for 6 groups of implants with Sa ranging from $0.7 \mu \mathrm{m}$ to $1.4 \mu \mathrm{m}$ in a different study by the same author. ${ }^{28}$ These findings are in agreement with a review by Sennerby and Meredith, who reported that most researchers failed to establish that rough or smooth implant surfaces affected implant stability. ${ }^{29}$

\section{Conclusions}

The present study found that implant surface properties affected implant stability as determined by Ostell and Periotest measurements. After 2 weeks of healing, a statistically significant increase in the mean ISQ and decrease in mean PTV values for the HA-coated implants was observed. In the case of the $\mathrm{Al}_{2} \mathrm{O}_{3}$ gritblasted control implants, only the PTV values increased significantly with time. The implant surface chemistry rather than the surface roughness seams to improve implant stability. Further studies are required to evaluate the long-term bone reaction.

\section{ORCID iDs}

Magdalena Łukaszewska-Kuska (1) https://orcid.org/0000-0002-4163-0995 Piotr Krawczyk (1) https://orcid.org/0000-0001-6083-9316 Agnieszka Martyla (1) https://orcid.org/0000-0001-5205-5052

Wieslaw Hędzelek (1) https://orcid.org/0000-0002-1644-6678

Barbara Dorocka-Bobkowska (1) https://orcid.org/0000-0003-3659-7761

\section{References}

1. Szymańska J, Szpak P. Marginal bone loss around dental implants with conical and hexagonal implant-abutment interface: A literature review. Dent Med Probl. 2017;54(3):279-284.

2. Genç T, Duruel O, Kutlu HB, Dursun E, Karabulut E, Tözüm TF. Evaluation of anatomical structures and variations in the maxilla and the mandible before dental implant treatment. Dent Med Probl. 2018;55(3):233-240.

3. Lukaszewska-Kuska M, Wirstlein P, Majchrowski R, Dorocka-Bobkowska B. Osteoblastic cell behaviour on modified titanium surfaces. Micron. 2018;105:55-63.

4. Aparicio C, Lang NP, Rangert B. Validity and clinical significance of biomechanical testing of implant/bone interface. Clin Oral Implants Res. 2006;17(Suppl 2):2-7.

5. Łukaszewska-Kuska M, Krawczyk P, Martyla A, Hędzelek W, Dorocka-Bobkowska B. Hydroxyapatite coating on titanium endosseous implants for improved osseointegration: Physical and chemical considerations. Adv Clin Exp Med. 2018;27(8):1055-1059.

6. Narayanan R, Seshadri SK, Kwon TY, Kim KH. Calcium phosphatebased coatings on titanium and its alloys. J Biomed Mater Res B Appl Biomater. 2008;85(1):279-299.

7. Yang Y, Dennison D, Ong Jl. Protein adsorption and osteoblast precursor cell attachment to hydroxyapatite of different crystallinities. Int J Oral Maxillofac Implants. 2005;22(2):187-192.

8. O'Hare P, Meenan BJ, Burke GA, Byrne G, Dowling D, Hunt JA. Biological responses to hydroxyapatite surfaces deposited via a coincident microblasting technique. Biomaterials. 2010;31(3):515-522.

9. Wang C, Karlis GA, Anderson Gl, et al. Bone growth is enhanced by novel bioceramic coatings on Ti alloy implants. J Biomed Mater Res $A$. 2009;90(2):419-428.

10. Shen JW, Wu T, Wang Q, Pan $\mathrm{HH}$. Molecular simulation of protein adsorption and desorption on hydroxyapatite surfaces. Biomaterials. 2008;29(5):513-532.

11. Sun L, Berndt CC, Gross KA, Kucuk A. Material fundamentals and clinical performance of plasma-sprayed hydroxyapatite coatings: A review. J Biomed Mater Res. 2001;58(5):570-592.

12. Beamson G, Briggs D. High Resolution XPS of Organic Polymers: The Scienta ESCA 300 Database. Chichester, UK: John Wiley \& Sons; 1992.

13. Meredith N. Assessment of implant stability as a prognostic determinant. Int J Prosthodont. 1998;11(5):491-501.

14. van Steenberghe D, Tricio J, Naert I, Nys M. Damping characteristics of bone-to-implant interfaces. A clinical study with the Periotest device. Clin Oral Implants Res. 1995;6(1):31-39.

15. Cunha AC, Freitas AOA, Marquezan M, Nojima LI. Mechanical influence of thread pitch on orthodontic mini-implant stability. Braz Oral Res. 2015;29(1):1-6.

16. Schulte W, Lukas D. The Periotest method. Int Dent J. 1992;42(6):433-440.

17. Wennerberg A, Albrektson T. Effects of titanium surface topography on bone integration: A systematic review. Clin Oral Implants Res. 2009;20(Suppl 4):172-184.

18. Anselme K, Ponche A, Bigerelle $M$. Relative influence of surface topography and surface chemistry on cell response to bone implant materials. Part 2: Biological aspects. Proc Inst Mech Eng H. 2010;224(12):1487-1507.

19. Zareidoost A, Yousefpour M, Ghaseme B, Amanzadeh A. The relationship of surface roughness and cell response of chemical surface modification of titanium. J Mater Sci Mater Med. 2012;23(6):1479-1488.

20. Dorocka-Bobkowska B, Medyński D, Pryliński M. Recent advances in tissue conditioners for prosthetic treatment. A review. Adv Clin Exp Med. 2017;26(4):723-728.

21. Sul YT, Johansson CB, Kang Y, Jeon DG, Albrektsson T. Bone reactions to oxidized titanium implants with electrochemical anion sulphuric acid and phosphoric acid incorporation. Clin Implant Dent Relat Res. 2002;4(2):78-87. 
22. Geurs NC, Jeffcoat RL, McGlumphy EA, Reddy MS, Jeffcoat MK. Influence of implant geometry and surface characteristics on progressive osseointegration. Int J Oral Maxillofac Implants. 2002;17(6):811-815.

23. Røynesdal AK, Ambjørnsen E, Haanaes HR. A comparison of 3 different endosseous nonsubmerged implants in edentulous mandibles: A clinical report. Int J Oral Maxillofac Implants. 1999;14(4):543-548.

24. Sul YT. The significance of the surface properties of oxidized titanium to the bone response: Special emphasis on potential biochemical bonding of oxidized titanium implant. Biomaterials. 2003;24(22):3893-3907.

25. Meraw SJ, Reeve CM, Wollan PC. Use of alendronate in peri-implant defect regeneration. J Periodontol. 1999;70(2):151-158.

26. Vercaigne S, Wolke JG, Naert I, Jansen JA. Bone healing capacity of titanium plasma-sprayed and hydroxyapatite-coated oral implants. Clin Oral Implants Res. 1998;9(4):261-271.

27. Sul YT, Jönsson J, Yoon GS, Johansson C. Resonance frequency measurements in vivo and related surface properties of magnesium-incorporated, micropatterned and magnesium-incorporated TiUnite, Osseotite, SLA and TiOblast implants. Clin Oral Implants Res. 2009;20(10):1146-1155.

28. Sul YT, Byon E, Wennerberg A. Surface characteristics of electrochemically oxidized implants and acid-etched implants: Surface chemistry, morphology, pore configurations, oxide thickness, crystal structure, and roughness. Int J Oral Maxillofac Implants. 2008;23(4):631-640.

29. Sennerby L, Meredith N. Implant stability measurements using resonance frequency analysis: Biological and biomechanical aspects and clinical implications. Periodontol 2000. 2008;47:51-66. 
